\title{
Time-Dependent Descending Facilitation from the Rostral Ventromedial Medulla Maintains, But Does Not Initiate, Neuropathic Pain
}

\author{
Shannon E. Burgess, Luis R. Gardell, Michael H. Ossipov, T. Philip Malan Jr, Todd W. Vanderah, \\ Josephine Lai, and Frank Porreca
}

Departments of Pharmacology and Anesthesiology, University of Arizona, Tucson, Arizona 85724

\begin{abstract}
Although injury-induced afferent discharge declines significantly over time, experimental neuropathic pain persists unchanged for long periods. These observations suggest that processes that initiate experimental neuropathic pain may differ from those that maintain such pain. Here, the role of descending facilitation arising from developing plasticity in the rostral ventromedial medulla (RVM) in the initiation and maintenance of experimental neuropathic pain was explored. Tactile and thermal hypersensitivity were induced in rats by spinal nerve ligation (SNL). RVM lidocaine blocked SNL-induced tactile and thermal hypersensitivity on post-SNL days 6-12 but not on post-SNL day 3 . Lesion of RVM cells expressing $\mu$-opioid receptors with dermorphin-saporin did not prevent the onset of SNL-induced tactile and thermal hypersensitivity, but these signs reversed to baseline levels beginning on post-SNL day 4. Similarly, lesions of the dorsolateral funiculus (DLF) did not prevent the onset of SNL-induced
\end{abstract}

Neuropathic pain may result from increased excitability of injured nerves (Kirk, 1974; Wall and Gutnick, 1974a,b). Persistent spontaneous afferent input also results in sensitization of spinal neurons to promote enhanced pain (Devor, 1991; Woolf, 1991; Woolf and Thompson, 1991). Agents that diminish spontaneous afferent activity are effective in clinical and experimental neuropathic pain (Chaplan et al., 1995; Chapman et al., 1998; Devor and Seltzer, 1999). Spontaneous afferent activity also correlates with expression of neuropathic pain (Han et al., 2000; C. Liu et al., 2000; X. Liu et al., 2000), and the onset of tactile hypersensitivity occurs with the development of afferent discharge (C. Liu et al., 2000). Discharges are most pronounced 1 week after injury but diminish significantly and rapidly over time (Han et al., 2000). Nerve injury elicits a fourfold to sixfold increase in spontaneous ectopic discharge within $24 \mathrm{hr}$ but is largely reduced by postinjury day 5 (C. Liu et al., 2000). Notably, however, once developed, behavioral signs of neuropathic pain remain constant for many weeks (Chaplan et al., 1994; Bian et al., 1999; Malan et al., 2000) despite the diminished rate of afferent discharge. These observations suggest the possibility that although the enhanced discharge associated with nerve injury may be critical in the initiation of neuropathic pain, such increased afferent activity may be insufficient to maintain neuropathic pain in the absence of other mechanisms.

Received Jan. 31, 2002; revised March 5, 2002; accepted March 18, 2002.

Correspondence should be addressed to Dr. Frank Porreca, Department of Pharmacology, College of Medicine, University of Arizona Health Sciences Center, Tucson, AZ 85724. E-mail: frankp@u.arizona.edu.

Copyright $\odot 2002$ Society for Neuroscience $0270-6474 / 02 / 225129-08 \$ 15.00 / 0$ tactile and thermal hypersensitivity, but these signs reversed to baseline levels beginning on post-SNL day 4. Lesions of the DLF also blocked the SNL-induced increase in spinal dynorphin content, which has been suggested to promote neuropathic pain. These data distinguish mechanisms that initiate the neuropathic state as independent of descending supraspinal influences and additional mechanism(s) that require supraspinal facilitation to maintain such pain. In addition, the data indicate that these timedependent descending influences can underlie some of the SNLinduced plasticity at the spinal level. Such time-dependent descending influences driving associated spinal changes, such as the upregulation of dynorphin, are key elements in the maintenance, but not initiation, of neuropathic states.

Key words: descending facilitation; neuropathic pain; RVM; lidocaine; tactile hypersensitivity; thermal hyperalgesia; dermorphin-saporin
Descending facilitation arising from neuroplastic changes occurring in the rostral ventromedial medulla (RVM) and projecting to the spinal dorsal horn through the dorsolateral funiculus (DLF) has been suggested to be necessary for expression of neuropathic pain (Ossipov et al., 2001). Blocking descending facilitation by lesions of the DLF, RVM microinjection of lidocaine, or

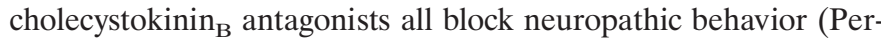
tovaara et al., 1996; Kovelowski et al., 2000; Ossipov et al., 2000). Selective lesioning of RVM cells expressing $\mu$-opioid receptors also blocks neuropathic behaviors (Porreca et al., 2001). However, the role of descending facilitation in the processes that initiate or maintain the expression of neuropathic pain is not known.

Peripheral nerve injury is known to elevate spinal dynorphin content, which may promote nociception (Kajander et al., 1990; Bian et al., 1999; Claude et al., 1999; Malan et al., 2000). Spinal dynorphin content is maximal by post-spinal nerve ligation (SNL) day 10 (Malan et al., 2000). Prodynorphin knock-out mice demonstrated tactile and thermal hypersensitivity that fully reversed to preinjury baselines within $8 \mathrm{~d}$ after SNL, whereas the wild-type mice sustained pain (Wang et al., 2001). Neuropathic behaviors were reversed by dynorphin antiserum in wild-type mice in late but not early periods after injury, suggesting that dynorphin is required for sustained expression of pain (Wang et al., 2001). The late time course of SNL-induced spinal dynorphin upregulation suggests the novel possibility that some of the nerve injuryinduced spinal plasticity may be secondary to neuroplasticity in other parts of the nervous system. One possibility is that spinal dynorphin upregulation may depend on developing neuroplasticity in the RVM. The present experiments explore the hypothesis 
that descending facilitation from the RVM develops over time and influences the spinal upregulation of dynorphin. These processes may be essential in the maintenance of experimental neuropathic pain.

\section{MATERIALS AND METHODS}

Male Sprague Dawley rats (Harlan, Indianapolis, IN), 200-300 gm at time of testing, were maintained in a climate-controlled room on a $12 \mathrm{hr}$ light/dark cycle (lights on at 06:00 A.M.) with food and water available ad libitum. All testing was performed in accordance with the policies and recommendations of the International Association for the Study of Pain and the National Institutes of Health guidelines for the handling and use of laboratory animals and received approval from the Institutional Animal Care and Use Committee of the University of Arizona.

Surgical procedures. Rats were prepared for bilateral RVM drug administration by placing anesthetized $(100 \mathrm{mg} / \mathrm{kg}$ ketamine/xylazine, i.p.) animals in a stereotaxic headholder. For intracranial bilateral drug administrations, the skull was exposed and two 26 ga guide cannula separated by $1.2 \mathrm{~mm}$ (Plastics One Inc., Roanoke, VA) were directed toward the lateral portions of the RVM (anteroposterior, $-11.0 \mathrm{~mm}$ from bregma; lateral, $\pm 0.6 \mathrm{~mm}$ from midline; dorsoventral, $-8.5 \mathrm{~mm}$ from the cranium) (Paxinos and Watson, 1986) and cemented in place. Drug administrations into the RVM were performed by slowly expelling $0.5 \mu \mathrm{l}$ of drug solution or saline through a 33 ga injection cannula inserted through the guide cannula and protruding an additional $1 \mathrm{~mm}$ into fresh brain tissue to prevent backflow of drug into the guide cannula. At the termination of the experiments, pontamine blue was injected into the site of the RVM injections and cannula placement was verified histologically. Data from animals with incorrectly placed cannula were discarded. Dermorphin, saporin, dermorphin-saporin (Advanced Targeting Systems, San Diego, CA), or vehicle were administered as a single dose of 3 pmol into the RVM (1.5 pmol in $0.5 \mu \mathrm{l}$ each side). Lidocaine was given in a dose of $4 \% \mathrm{w} / \mathrm{v}$ in $0.5 \mu \mathrm{l}$.

$S N L$. Tight ligation of the $\mathrm{L}_{5} / \mathrm{L}_{6}$ spinal nerve was performed according to the method of Kim and Chung (1992). The rats were maintained under anesthesia with halothane vaporized in $95 \% \mathrm{O}_{2}$ and $5 \% \mathrm{CO}_{2}$. After surgical preparation of the rats and exposure of the dorsal vertebral column from $\mathrm{L}_{4}$ to $\mathrm{S}_{2}$, the exposed $\mathrm{L}_{5}$ and $\mathrm{L}_{6}$ spinal nerves were tightly ligated with 4-0 silk suture. The incision was closed, and the animals were allowed to recover. Rats that exhibited motor deficiency or a lack of subsequent increased sensitivity to innocuous mechanical stimulation were excluded from additional testing. Sham control rats underwent the same operation and handling as the experimental animals, but without SNL.

Spinal DLF lesions. Spinal lesions at $\mathrm{T}_{8}$ were performed in halothaneanesthetized rats as described previously (Kovelowski et al., 1999; Ossipov et al., 2000). The spinal cord was exposed by laminectomy and the DLF was crushed with fine forceps. Sham spinal surgery was performed by exposing the vertebrae and performing the laminectomy, but without cutting any neuronal tissue. Hemostasis was confirmed and the wound over the exposed spinal cord was packed with gelfoam and closed. All lesions were verified histologically at the termination of the experiment by fixing the spinal sections obtained from the lesion site in paraffin. Sections (40 $\mu \mathrm{m}$ thick) were mounted and stained with Luxor Fast Blue myelin stain to visualize intact and disrupted white matter. Behavioral results and dynorphin content obtained only from animals that had appropriately placed DLF lesions were included in analysis.

Thermal hyperalgesia. The method of Hargreaves et al. (1988) was used to assess paw-withdrawal latency to a thermal nociceptive stimulus. Rats were allowed to acclimate within Plexiglas enclosures on a clear glass plate maintained at $30^{\circ} \mathrm{C}$. A radiant heat source (i.e., high-intensity projector lamp) was activated with a timer and focused onto the plantar surface of the hindpaw. Paw-withdrawal latency was determined by a motion detector that halted both lamp and timer when the paw was withdrawn. A maximal cutoff of $40 \mathrm{sec}$ was used to prevent tissue damage. Significant changes from baseline control values were detected by ANOVA followed by the post hoc least significance test. Significance was set at $p \leq 0.05$.

Tactile hypersensitivity. The paw-withdrawal thresholds of the hindpaws of the rats were determined in response to probing with eight calibrated von Frey filaments (Stoelting, Wood Dale, IL) in logarithmically spaced increments ranging from 0.41 to $15 \mathrm{gm}(4-150 \mathrm{mN})$. Each filament was applied perpendicularly to the plantar surface of the ligated paw of rats kept in suspended wire-mesh cages. Withdrawal threshold was deter- mined by sequentially increasing and decreasing the stimulus strength ("up and down" method), analyzed using a Dixon nonparametric test (Chaplan et al., 1994) and expressed as the mean withdrawal threshold. Significant changes from baseline control values were detected by ANOVA followed by the post hoc least significance test. Significance was set at $p \leq 0.05$.

Dynorphin enzyme immunoassay. Spinal dynorphin content was assayed as described previously (Malan et al., 2000). The dorsal quadrant of lumbar spinal cord from the ipsilateral side of sham-operated or ligated rats was placed in $1 \mathrm{~m}$ acetic acid, disrupted with a Polytron homogenizer (Kinematica Kriens, Lucerne, Switzerland), and boiled at $95^{\circ} \mathrm{C}$ for $20 \mathrm{~min}$. The samples were centrifuged at $10,000 \times g$ for $20 \mathrm{~min}$ at $4^{\circ} \mathrm{C}$. The supernatant was analyzed for protein content and lyophilized. A commercial enzyme immunoassay system using anti-dynorphin $\mathrm{A}_{(1-17)}$ antiserum (Peninsula Laboratories, Belmont, CA) was used to determine the content of dynorphin in the spinal cord extracts against a standard curve of dynorphin $\mathrm{A}_{(1-17)}$. The reaction product is quantified by absorbance at $450 \mathrm{~nm}$. Standard curves were constructed, and the dynorphin content was determined with Prism (GraphPad Software, San Diego, CA). Pairwise comparisons between treatments were detected using Student's $t$ test. Significance was determined at $p \leq 0.05$.

\section{RESULTS RVM lidocaine}

Behavioral signs of tactile hypersensitivity and thermal hyperalgesia were clearly evident within $3 \mathrm{~d}$ after SNL (Fig. 1). The preligation baseline paw-withdrawal threshold to probing with von Frey filaments was $14.25 \pm 0.30 \mathrm{gm}$ and the paw-withdrawal latency to noxious radiant heat was $21.0 \pm 0.19 \mathrm{sec}$ (Fig. 2). After SNL, the paw-withdrawal threshold was significantly $(p \leq 0.05)$ reduced to $3.67 \pm 0.44 \mathrm{gm}$ and the paw-withdrawal latency was significantly $(p \leq 0.05)$ reduced to $14.5 \pm 0.20 \mathrm{sec}$ (Fig. 2). In contrast, sham surgery had no significant effect on behavioral signs of neuropathic pain; the postsurgical paw-withdrawal tactile threshold and thermal latency were $14.5 \pm 0.37 \mathrm{gm}$ and $20.5 \pm$ $0.38 \mathrm{sec}$, respectively (Fig. 2). The bilateral microinjection of lidocaine $(4 \% \mathrm{w} / \mathrm{v} ; 0.5 \mu \mathrm{l})$ or saline into the RVM on day 3 after SNL did not elicit any changes in paw-withdrawal thresholds to probing with von Frey filaments (Fig. $1 A$ ) or to noxious radiant heat over the $60 \mathrm{~min}$ observation period (Fig. 1B). The pawwithdrawal threshold to von Frey filaments was $4.13 \pm 0.77 \mathrm{gm} 10$ min after lidocaine (Fig. $1 A$ ), and the paw-withdrawal latency to noxious heat was $14.3 \pm 0.45 \mathrm{sec} 10 \mathrm{~min}$ after lidocaine (Fig. $1 B$ ). However, behavioral manifestations of neuropathic pain were reversed when lidocaine was microinjected into the RVM on the sixth day after SNL (Fig. 1C,D). The maximal effect of lidocaine was observed 10 min after microinjection into the RVM, significantly $(p \leq 0.05)$ raising paw-withdrawal thresholds to light tactile stimuli to $11.7 \pm 1.0 \mathrm{gm}$ (Fig. $1 C$ ) and mean pawwithdrawal latencies to radiant heat to $19.4 \pm 1.46 \mathrm{sec}$ (Fig. 1D). The blockade of tactile hypersensitivity and thermal hyperalgesia by RVM lidocaine rapidly returned to baseline values within 30 min of the injection. Similarly, lidocaine microinjected into the RVM also reversed signs of neuropathic pain on the ninth and 12th day after SNL (Fig. 2). The paw-withdrawal thresholds to probing with von Frey filaments were significantly $(p \leq 0.05)$ elevated to $12.1 \pm 0.77$ and $12.4 \pm 0.76$ gm, respectively, on those days (Fig. 2A). Similarly, the paw-withdrawal latencies to radiant heat were significantly $(p \leq 0.05)$ elevated to $19.8 \pm 1.63$ and $20.0 \pm 0.73 \mathrm{sec}$ on the same days (Fig. $2 B$ ). Furthermore, the effects of lidocaine against behavioral signs of neuropathic pain were maximal at $10 \mathrm{~min}$ after microinjection and returned to baseline values by $30 \mathrm{~min}$ (data not shown). Microinjection of lidocaine into the RVM did not alter responses to either tactile or thermal stimuli in the sham-operated rats over the entire course 
A

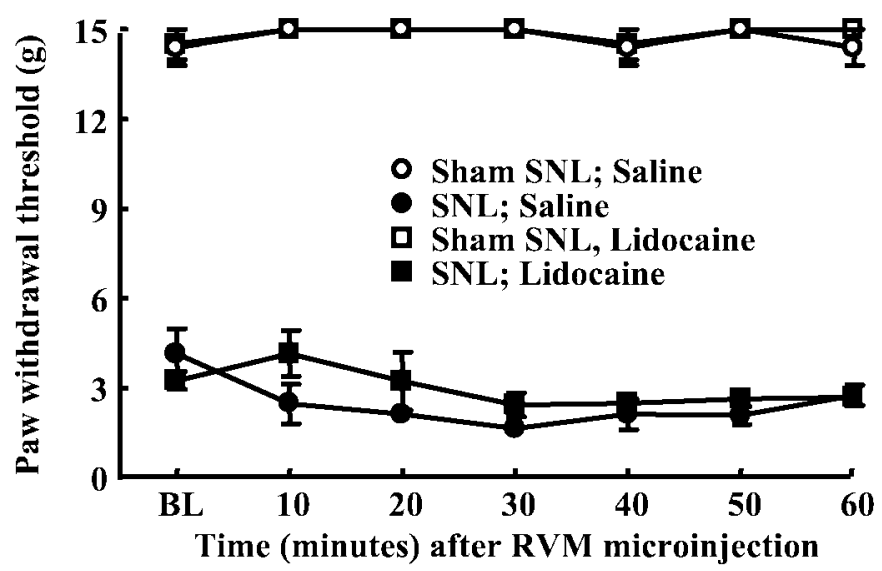

C

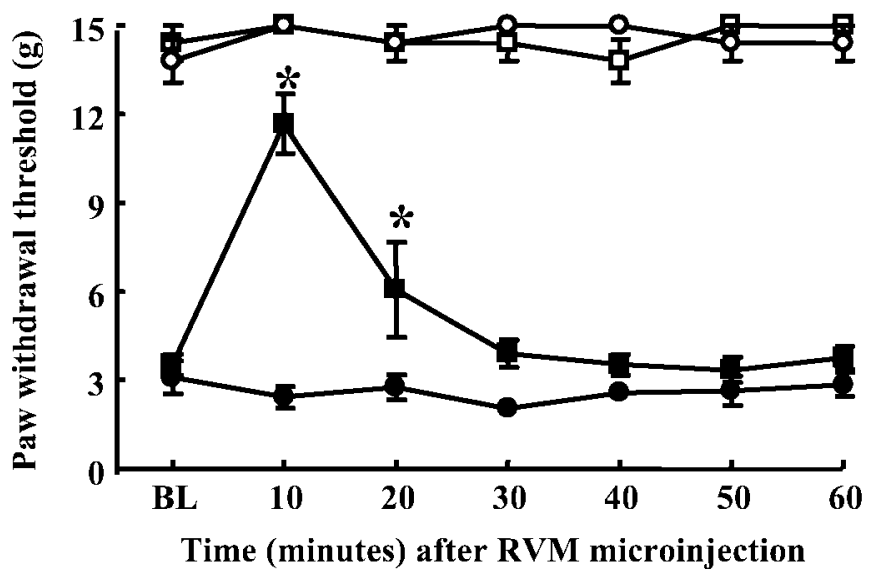

B

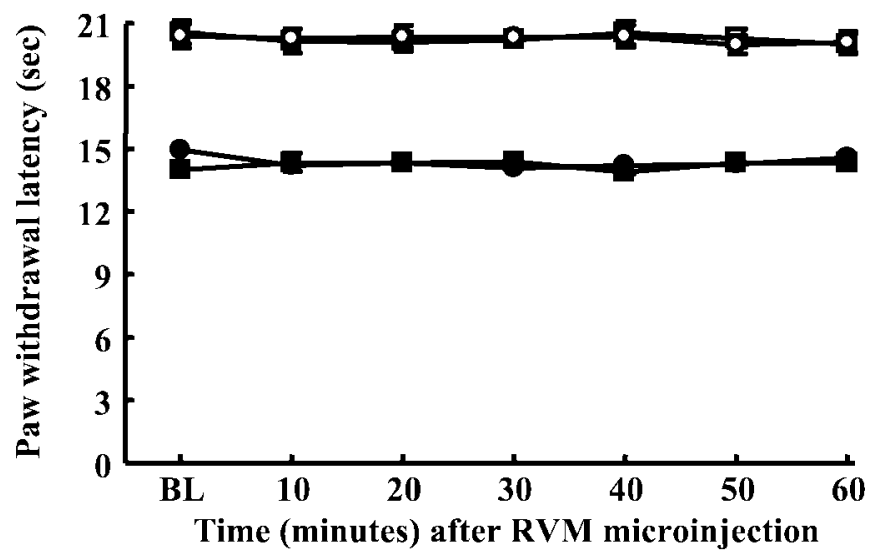

D

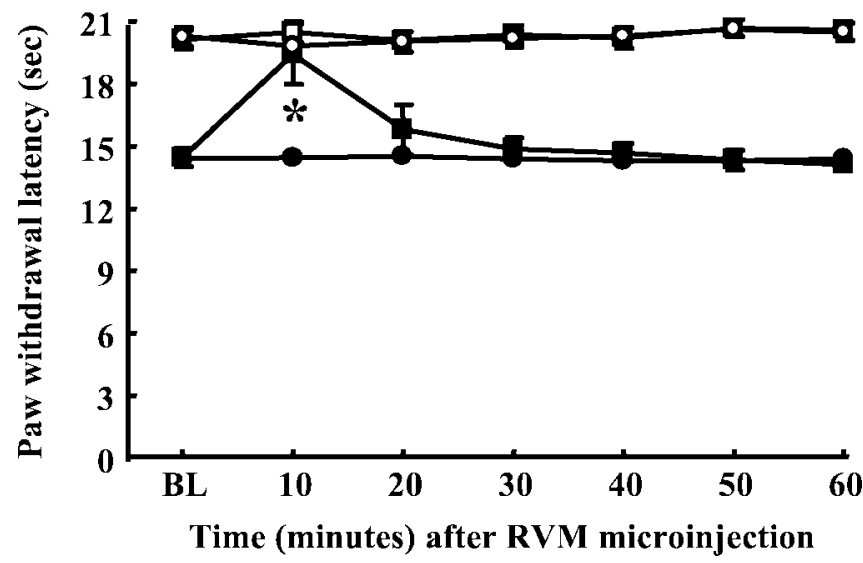

Figure 1. Lidocaine $(4 \% \mathrm{w} / \mathrm{v})$ or saline was microinjected bilaterally into the RVM of sham-operated male Sprague Dawley rats and of rats with $\mathrm{L}_{5} / \mathrm{L}_{6}$ SNL 3 and $6 \mathrm{~d}$ after nerve injury. Baseline responses to tactile and thermal stimuli were determined in sham-operated and SNL rats before injections $(B L)$. Tactile hypersensitivity $(A, C)$ and thermal hyperalgesia $(B, D)$, indicated by significant decreases in the response thresholds, were measured at 10 min intervals for $60 \mathrm{~min}$ after each lidocaine or saline microinjection. Lidocaine did not reverse tactile hypersensitivity and thermal hyperalgesia on post-SNL day $3(A, B)$ but was effective on day $6(C, D)$. Behavioral responses were not altered by lidocaine in sham-operated rats or by saline in either group. ${ }^{*} p \leq 0.05$ compared with pre-SNL values.

of the study. Furthermore, the microinjection of saline into the RVM of either sham-operated or SNL rats did not produce any changes in either tactile or thermal responses over the time course of this study (Fig. 2).

\section{Dermorphin-saporin microinjection}

Rats received a single bilateral injection of saline $(0.5 \mu \mathrm{l})$, dermorphin (3 pmol), saporin (3 pmol), or the dermorphin-saporin conjugate ( 3 pmol) into the RVM. Our previous investigations revealed that this protocol of dermorphin-saporin treatment elicited a selective loss of RVM neurons expressing the $\mu$-opioid receptor at postinjection day 28 (Porreca et al., 2001). These microinjections did not produce any changes in the baseline hindpaw responses to probing with von Frey filaments or to noxious radiant heat when evaluated after $28 \mathrm{~d}$ (Fig. 3). On the 28th day after the RVM microinjections, each of the pretreated groups was divided into two groups, one receiving $\mathrm{L}_{5} / \mathrm{L}_{6} \mathrm{SNL}$ and the other receiving sham surgery. The behavioral responses to light tactile and noxious heat stimuli were measured on a daily basis. None of the groups of rats with sham surgery demonstrated any significant decreases in behavioral responses to either tactile or thermal stimuli over the entire $14 \mathrm{~d}$ observation period (Fig. 3). All groups of rats with SNL demonstrated tactile hypersensitivity and thermal hyperalgesia evident by the second day after SNL. Paw-withdrawal thresholds to light tactile stimuli ranged between $14.4 \pm 0.6$ and $15 \pm 0$ gm before SNL and were significantly ( $p \leq$ 0.05 ) reduced to between $3.7 \pm 0.84$ and $4.9 \pm 1.85$ gm (Fig. $3 A$ ). Similarly, the paw-withdrawal latencies to noxious heat ranged from $19.9 \pm 0.56$ to $20.3 \pm 0.23 \mathrm{sec}$ before SNL and were significantly $(p \leq 0.05)$ reduced to between $14.0 \pm 0.38$ and $15.8 \pm 0.46 \mathrm{sec}$ by the second day after SNL (Fig. $3 B$ ). Tactile and thermal hypersensitivity remained evident throughout the $14 \mathrm{~d}$ observation period in the rats with SNL that were pretreated with 

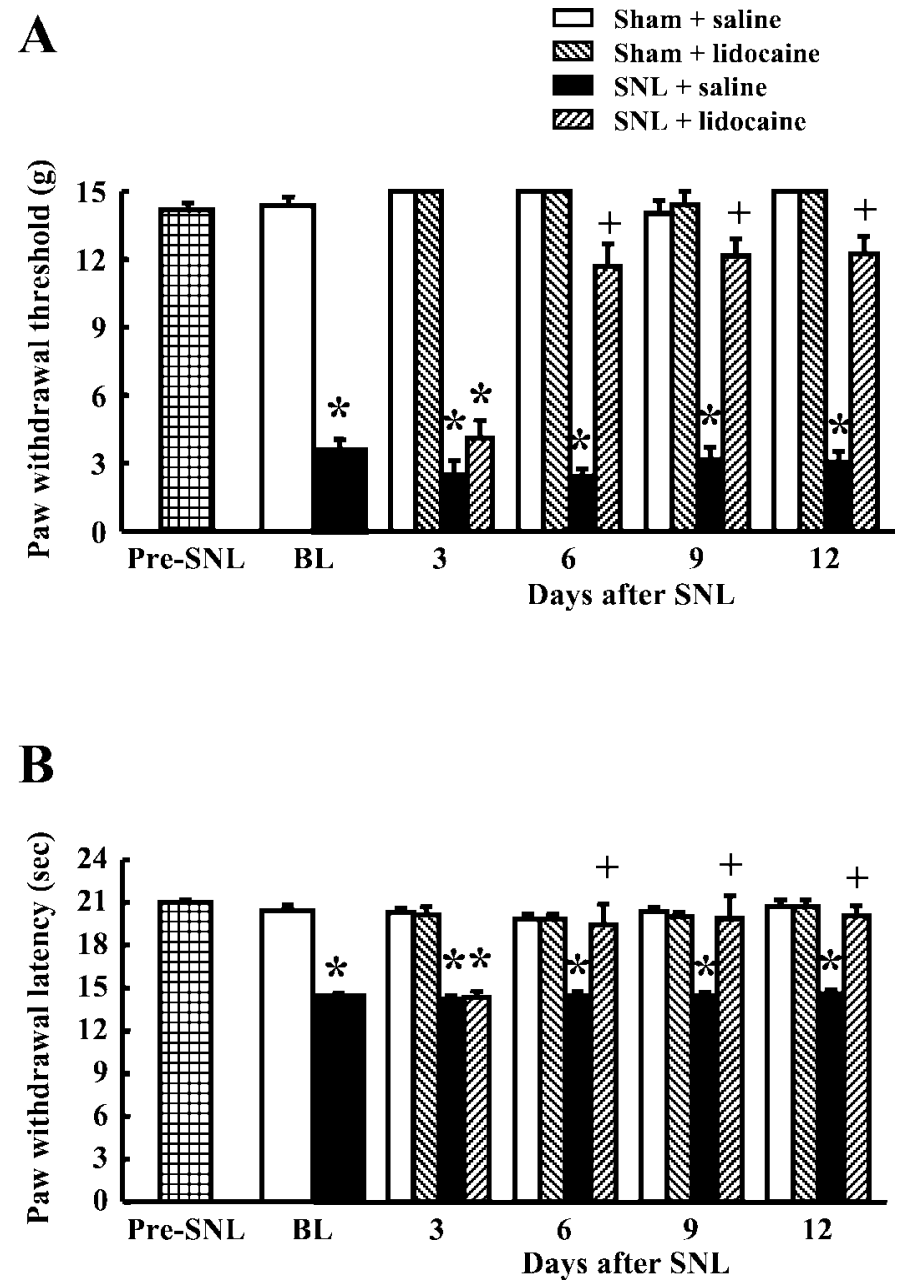

Figure 2. Lidocaine (4\% w/v) or saline was microinjected bilaterally into the RVM of sham-operated male Sprague Dawley rats and of rats with $\mathrm{L}_{5} / \mathrm{L}_{6} \mathrm{SNL} 3,6,9$, and $12 \mathrm{~d}$ after nerve injury. Baseline responses to tactile and thermal stimuli were determined before surgery (pre-SNL) and on day 3 after surgery before injections $(B L)$. Tactile hypersensitivity $(A)$ and thermal hyperalgesia $(B)$, indicated by significant decreases in the response thresholds, were measured 10 min after each lidocaine or saline microinjection. Lidocaine did not reverse tactile hypersensitivity and thermal hyperalgesia on post-SNL day 3 but was effective thereafter. Behavioral responses were not altered by lidocaine in sham-operated rats or by saline in either group. ${ }^{*} p \leq 0.05$ compared with pre-SNL values; ${ }^{+} p \leq 0.05$ compared with SNL baseline values.

saline, dermorphin, or saporin microinjected into the RVM (Fig. $3)$. In contrast, the rats that were pretreated with dermorphinsaporin demonstrated a time-related reversal of heightened sensitivity to tactile and thermal stimuli that was seen beginning at the fifth day after SNL; ultimately these thresholds were not significantly different from pre-SNL baseline values (Fig. 3).

\section{DLF lesions}

Rats received either lesions of the DLF or sham surgery at $T_{8}$. Each group was further subdivided and received either sham surgery or $\mathrm{L}_{5} / \mathrm{L}_{6} \mathrm{SNL}$ after an additional $7 \mathrm{~d}$. Neither sham DLF nor DLF lesions caused any changes in behavioral responses to tactile or thermal stimuli. Paw-withdrawal thresholds to light touch were $15 \pm 0 \mathrm{gm}$ before and after spinal surgery, and the paw-withdrawal latencies to noxious radiant heat were $20.2 \pm 0.17$ sec before spinal surgery and $20.2 \pm 0.23 \mathrm{sec}$ after sham DLF and $20.1 \pm 0.25 \mathrm{sec}$ after DLF lesions (Fig. 4). Sham ligation did not

\section{A}

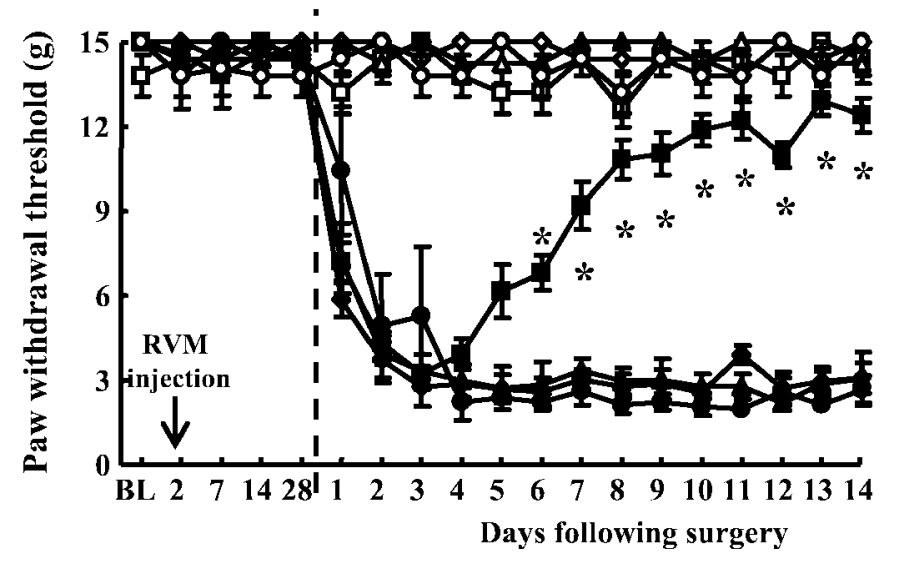

B

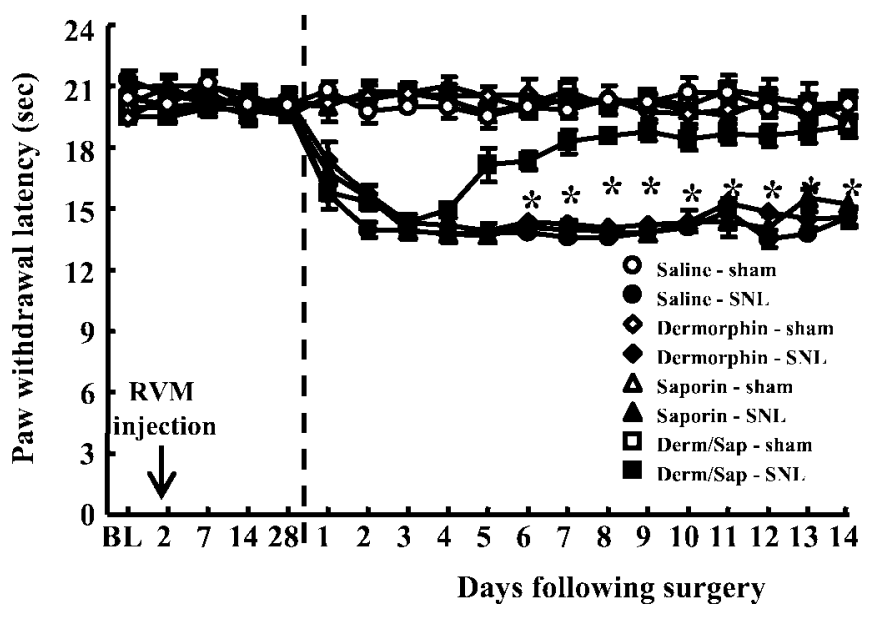

Figure 3. Male Sprague Dawley rats received bilateral microinjections of saline or of saporin, dermorphin, or the dermorphin-saporin conjugate (Derm/Sap) $(1.5 \mathrm{pmol}$ on each side of the RVM). After $28 \mathrm{~d}$, the rats were subjected to either $\mathrm{L}_{5} / \mathrm{L}_{6} \mathrm{SNL}$ or sham surgery. Vertical dashed lines represent time of surgery. Paw-withdrawal thresholds to light tactile stimuli $(A)$ and to noxious radiant heat $(B)$ were determined before microinjections $(B L)$, weekly after the microinjections, and daily for $14 \mathrm{~d}$ after SNL or sham surgery. Tactile hypersensitivity $(A)$ and thermal hyperalgesia $(B)$ were evident in all groups with SNL during the initial $4 \mathrm{~d}$ of testing, as indicated by the significant decreases in response thresholds. However, the rats pretreated with the dermorphin-saporin conjugate demonstrated clear reversal of SNL-induced threshold changes commencing at postsurgery day $5 .{ }^{*} p \leq 0.05$ compared with premicroinjection values.

produce any significant decreases in behavioral responses to either light tactile stimuli or noxious radiant heat over the entire $14 \mathrm{~d}$ observation period (Fig. 4). Both groups of rats with SNL demonstrated tactile hypersensitivity and thermal hyperalgesia by the second day after SNL. Paw-withdrawal thresholds of the sham-operated and DLF-lesioned rats to light tactile stimuli were significantly $(p \leq 0.05)$ reduced to $3.94 \pm 0.57$ and $2.76 \pm 0.48$ gm, respectively (Fig. $4 A$ ). Similarly, the paw-withdrawal latencies of the sham-operated and DLF-lesioned rats to noxious heat were significantly $(p \leq 0.05)$ reduced to $14.6 \pm 0.27$ and $13.8 \pm$ $0.38 \mathrm{sec}$, respectively, on the second day after SNL (Fig. 4B). The behavioral responses of the rats with SNL and sham DLF surgery remained constant throughout the $14 \mathrm{~d}$ observation period. In 
A

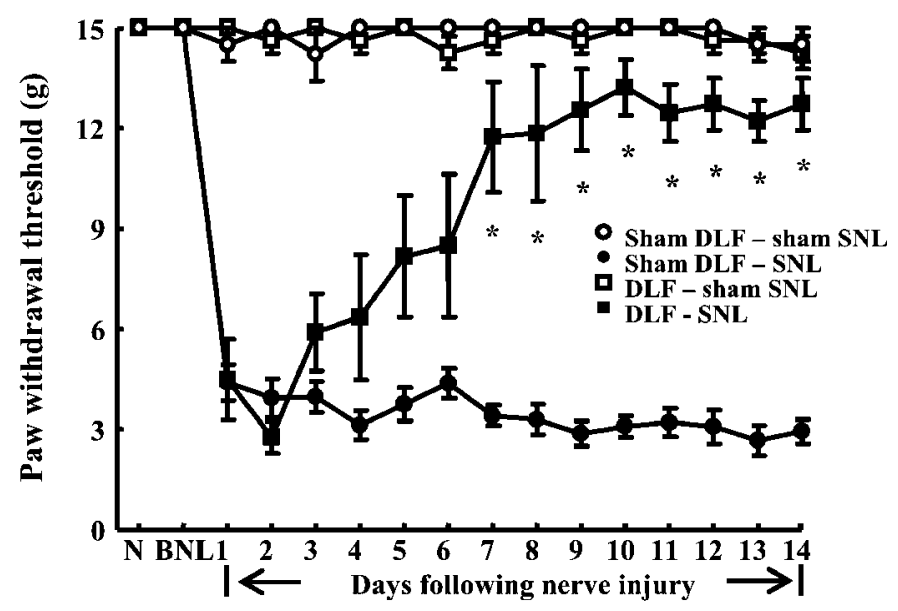

B

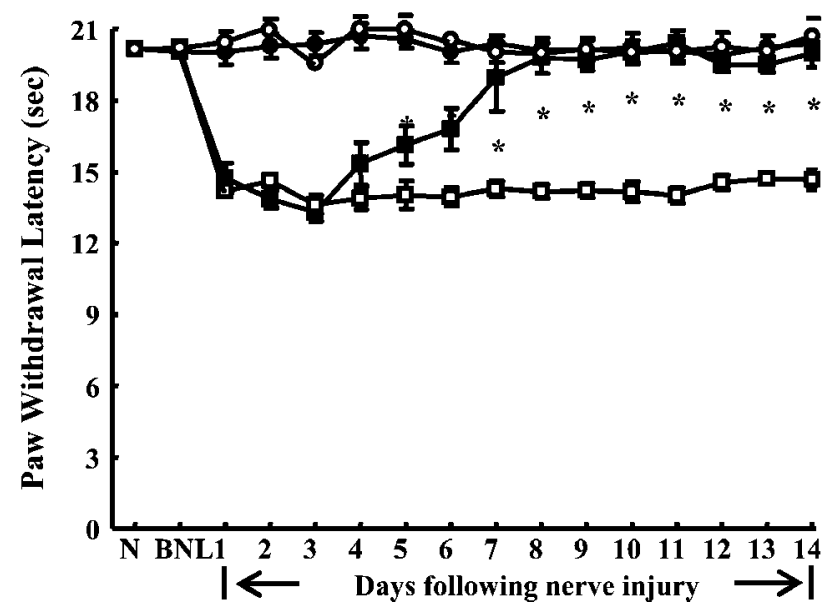

Figure 4. Male Sprague Dawley rats received bilateral surgical lesions of the DLF or sham DLF surgery at $\mathrm{T}_{8}$. After $7 \mathrm{~d}$, the rats were subjected to either $\mathrm{L}_{5} / \mathrm{L}_{6} \mathrm{SNL}$ or sham surgery. Paw-withdrawal thresholds to light tactile stimuli $(A)$ and to noxious radiant heat $(B)$ were determined before spinal surgery before SNL $(B N L)$ and daily for $14 \mathrm{~d}$ after SNL or sham surgery. Tactile hypersensitivity $(A)$ and thermal hyperalgesia $(B)$ were evident in all groups with SNL during the initial $4 \mathrm{~d}$ of testing, as indicated by the significant decreases in behavioral responses. However, the rats that received both $\mathrm{L}_{5} / \mathrm{L}_{6}$ SNL and lesions of the DLF demonstrated a clear reversal of SNL-induced threshold changes commencing at postsurgery days $4-5$. * $p \leq 0.05$ compared with premicroinjection values. $N$, Naive.

contrast, the heightened sensory responses of the rats with SNL and DLF lesions began a gradual return to pre-SNL baseline values within 4-5 d after SNL (Fig. 4). The paw-withdrawal threshold to light tactile stimuli was significantly $(p \leq 0.05)$ increased to $11.7 \pm 1.66 \mathrm{gm}$, and the paw-withdrawal latency to radiant heat was significantly $(p \leq 0.05)$ increased to $18.9 \pm 1.42$ sec by the seventh day after SNL (Fig. 4).

\section{Spinal dynorphin content}

Spinal cords were extruded and assayed for dynorphin content in the dorsal quadrant ipsilateral to SNL or sham ligation on the 10 th day after surgery. This time point was chosen because our previous investigations demonstrated that dynorphin levels were

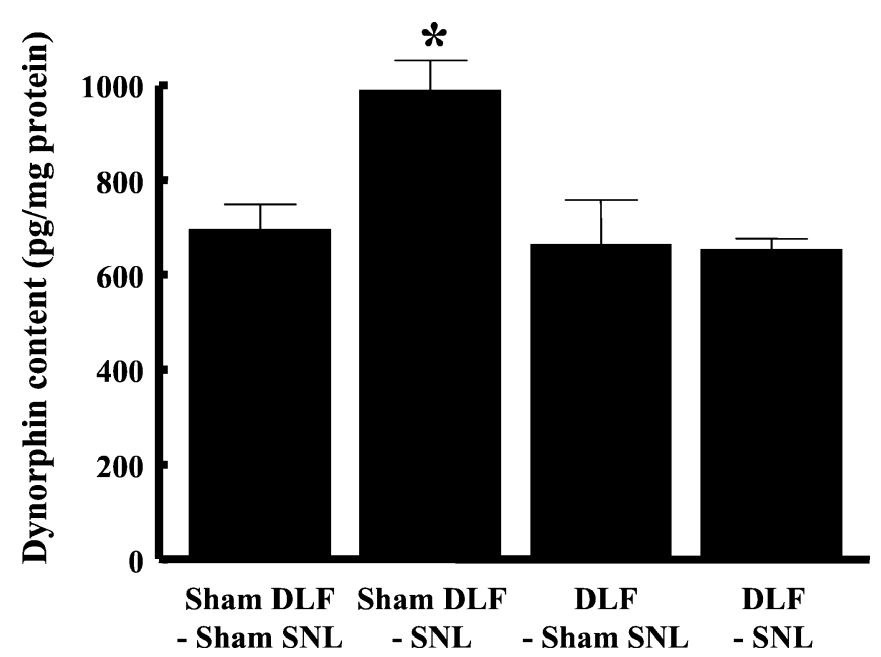

Figure 5. The spinal cords of sham-operated rats (sham SNL) and rats with $\mathrm{L}_{5} / \mathrm{L}_{6} \mathrm{SNL}$ that had received either lesions of the DLF or sham spinal surgery (sham DLF) were removed on day 10 after surgery. The dorsal half of the lumbar cord was isolated and assayed for dynorphin content with enzyme immunoassay. The rats with SNL that had also received sham DLF surgery showed a significant ( $p \leq 0.05$; Student's $t$ test) increase in spinal dynorphin content when compared with the sham $\mathrm{SNL} /$ sham DLF group. In contrast, the spinal dynorphin content of the rats with SNL or sham SNL that also received lesions of the DLF was not significantly different ( $p>0.05$; Student's $t$ test) than that of the $\mathrm{SNL} /$ sham DLF group.

maximally increased at this time point (Malan et al., 2000). Rats with sham DLF lesions and $\mathrm{L}_{5} / \mathrm{L}_{6} \mathrm{SNL}$ demonstrated a significant $(p \leq 0.05)$ elevation in spinal dynorphin content $10 \mathrm{~d}$ after SNL. The spinal dynorphin content of rats with sham DLF lesion and with SNL was $991 \pm 63 \mathrm{pg}$ dynorphin/mg protein, whereas that of rats with sham DLF lesion and sham SNL was $698 \pm 53 \mathrm{pg}$ dynorphin/mg protein (Fig. 5). In contrast, lesions of the DLF prevented the elevation in spinal dynorphin content. The spinal dynorphin content in the rats with SNL and DLF lesions was $656 \pm 22 \mathrm{pg}$ dynorphin/mg protein, which was not significantly different $(p>0.05)$ from that of the control group (Fig. 5). Rats with DLF lesions and sham SNL surgery also had a spinal dynorphin level $(667 \pm 93 \mathrm{pg}$ dynorphin/mg protein) that was similar to that seen for the rats with sham DLF and sham SNL surgery.

\section{DISCUSSION}

The results of the present experiments provide supporting evidence for the hypothesis that mechanisms that initiate neuropathic pain differ from those that maintain such pain. In addition, the data support the hypothesis that some of the nerve injuryinduced plasticity occurring at the spinal level may be secondary to developing plasticity in other regions of the neuroaxis. Although the initiation of neuropathic pain is likely to be mediated by increased afferent drive occurring shortly after the injury, such enhanced activity is insufficient to maintain the neuropathic state in the absence of time-related development of descending facilitation arising in the RVM and an attendant elevation in spinal dynorphin content. The need for descending modulatory influences and enhancement of spinal dynorphin does not exclude the possibility of other mechanisms that may also be important in maintaining the neuropathic state.

Considerable evidence supports the importance of afferent drive as a mechanism of neuropathic pain (for review, see Devor 
et al., 1992; Dickenson et al., 2001). Behavioral signs of neuropathic pain in nerve-injured mice were blocked by spinal (+)-5methyl-10,11-dihydro-5H-dibenzo [a,d] cyclohepten-5,10-imine maleate (MK-801) at postinjury day 3, although they were insensitive to dynorphin antiserum at this time, suggesting the importance of excitatory transmission possibly arising in part from increased afferent input (Wang et al., 2001). Tactile and thermal hypersensitivity in nerve-injured rats was significantly attenuated by the application of lidocaine directly at the injury site (Ossipov et al., 1995; Kovelowski et al., 2000; Malan et al., 2000) and local lidocaine application has been used to successfully treat postherpetic neuralgia (Rowbotham et al., 1995, 1996). These observations suggest that enhanced afferent discharge is an important component of the neuropathic state at both the initial stage and at subsequent stages after injury. Experimental observations also confirm, however, that although maintained above preinjury baselines, spontaneous ectopic activity diminishes quite rapidly within the first week after injury (Han et al., 2000; C. Liu et al., 2000; X. Liu et al., 2000). Despite the diminishing afferent input over time, the behavioral hypersensitivity remains unchanged for many weeks once it is established, suggesting that other mechanisms may be also necessary to maintain the neuropathic state.

Previous work has shown that the behavioral expression of neuropathic pain is dependent on descending facilitatory systems that arise in the RVM. Such facilitation may be time dependent, resulting from plasticity in the RVM and may act to further enhance the now diminished afferent input from injured (Devor and Seltzer, 1999) or adjacent (Tal and Bennett, 1994; Yoon et al., 1996; Wu et al., 2001) fibers. Evidence supports a role for pontine-medullary sites in the manifestation of experimental neuropathic pain (Pertovaara et al., 1996, 2001; Kovelowski et al., 2000). Manipulations that disrupt communication between the brain and spinal cord have been shown to block the expression of tactile and thermal hypersensitivity. Spinal transection and hemisection eliminate nerve injury-induced tactile hypersensitivity, indicating the critical contribution of a supraspinal component in the expression of neuropathic pain (Bian et al., 1998; Kauppila et al., 1998; Sun et al., 2001). Similarly, enhanced responses of wide dynamic-range neurons to tactile stimuli induced by mustard oil are blocked by transection of the spinal cord (Mansikka and Pertovaara, 1997; Pertovaara, 1998).

The RVM has been well characterized in regard to spinopetal modulatory control of nociception mediating both inhibition and facilitation of nociception (Fields, 1992; Zhuo and Gebhart, 1992, 1997). Persistent input from injured or adjacent fibers to supraspinal sites (Sun et al., 2001) may ultimately elicit neuroplastic changes within the RVM that might elicit a time-related activation of descending facilitation. One possibility for such descending facilitation is the class of RVM neurons identified as "ON" cells, because they accelerate firing immediately before a nociceptive reflex occurs (Fields et al., 1983; Fields and Heinricher, 1985; Fields, 1992; Heinricher et al., 1992; Heinricher and Roychowdhury, 1997). Enhanced nociceptive sensitivity has been noted when ON cell activity is increased (Heinricher et al., 1989; Bederson et al., 1990; Kim et al., 1990). Consistent with this, RVM lidocaine blocks both SNL-induced enhanced activity of spinal dorsal horn units and neuropathic behavior, suggesting the presence of a facilitatory influence from this region (Pertovaara et al., 1996, 2001; Mansikka and Pertovaara, 1997; Pertovaara, 1998; Kovelowski et al., 2000; Porreca et al., 2002). The possible time dependency of neuropathic pain on such descending facilitation has not been explored previously. The present studies reveal that descending influences are not apparent for the first $3 \mathrm{~d}$ after injury but are clearly present by day 6 , when RV M lidocaine blocks both SNL-induced tactile and thermal hypersensitivity. Critically, RVM lidocaine was inactive at postinjury day 3, suggesting that at this time, tonic activity of cells in this region is unlikely.

Evidence supports the possibility that RVM cells that mediate descending facilitation may express $\mu$-opioid receptors (Fields et al., 1983; Fields and Heinricher, 1989; Pan et al., 1990; Heinricher et al., 1994). It has been shown previously that dermorphinsaporin produced a partial lesion of $\mu$-opioid receptor-expressing neurons in the RVM and prevented as well as reversed the behavioral manifestation of neuropathic pain when evaluated at postinjury day 7 (Porreca et al., 2001). Similarly, selective ablation of the DLF, which includes the spinopetal projections from the RVM, also prevented and reversed experimental neuropathic pain behavior when evaluated at postinjury day 7 (Ossipov et al., 2000). Together, these observations provide strong evidence that descending facilitation from the RVM is a critical factor in the expression of pain. The present studies show that such descending facilitation does not play a role in the early phase of the postinjury state but seems to be critical to the maintenance of the neuropathic condition. Lesions of the DLF or of $\mu$-opioid receptorexpressing cells in the RVM show a reversal of SNL-induced behavior that is apparent by approximately postinjury day 5 and a return to preinjury baselines by approximately day 8 . The time course of the reversal of both tactile and thermal hypersensitivity after lesion of the DLF or of RVM cells with dermorphinsaporin is remarkably similar, suggesting that RVM plasticity over this time period and later is crucial to the neuropathic state. These data are also consistent with the observed reversible blockade of nerve injury-induced pain by RVM lidocaine.

The time course over which descending facilitation develops is also consistent with the time course of nerve injury-induced upregulation of spinal dynorphin content, which may provide insights into spinal mechanisms by which facilitation may occur. The relatively late peak in expression of spinal dynorphin after nerve injury (Malan et al., 2000; Wang et al., 2001) suggests the possibility that upregulation depends on the time-related development of descending modulatory influences and may ultimately function to maintain the neuropathic state. This possibility is supported by the data, because manipulations that blocked the maintained state of neuropathic pain also blocked the SNLinduced elevation of spinal dynorphin content. For example, disruption of the spinopetal tracts from the RVM through the DLF prevented SNL-induced upregulation levels of spinal dynorphin. Because neither DLF lesion or dorsal rhizotomy blocks basal expression of spinal dynorphin, it is highly likely that upregulation of dynorphin results from local interneurons (Cho and Basbaum, 1988). Significantly, lidocaine in the RVM also did not block neuropathic pain behaviors at postinjury day 3, a time at which spinal dynorphin is not significantly elevated, suggesting the presence of a transitional period for descending influence (Malan et al., 2000; Wang et al., 2001). Dynorphin antiserum was shown to abolish tactile and thermal hypersensitivity at postinjury day 14, but not at day 2, whereas MK-801 was effective at both time points (Wang et al., 2001). Finally, mice with deletions of the prodynorphin gene displayed the behavioral signs of neuropathic pain only up to postinjury day 5 , with complete reversal by day 8 , whereas wild-type littermates maintained pain for the entire $14 \mathrm{~d}$ observation period (Wang et al., 2001). These data are all consistent with the view that upregulation of spinal dynorphin is a 
mechanism that maintains the neuropathic state, perhaps through a nonopioid action, to enhance release of excitatory neurotransmitters such as glutamate or excitatory peptides from primary afferents (Faden, 1992; Skilling et al., 1992; Arcaya et al., 1999; Claude et al., 1999; Vanderah et al., 2001).

Our data provide evidence for the presence of time-related descending facilitatory influences arising in the RVM that are critical to the maintenance but not the initiation of experimental neuropathic pain. In addition, the data show the importance of descending influences in eliciting plasticity at the spinal level. It is not known whether other changes observed in the spinal dorsal horn after nerve injury similarly depend on descending influences. Together, these and possibly other events appear to be established by the initial processes of peripheral nerve injury to maintain the expression of abnormal pain. Patients experiencing neuropathic pain are likely to require intervention at time points substantially long after the precipitating injury has occurred, suggesting that the understanding of the processes that maintain neuropathic pain will be critically important in the development of rational approaches for therapeutic interventions.

\section{REFERENCES}

Arcaya JL, Cano G, Gomez G, Maixner W, Suarez-Roca H (1999) Dynorphin A increases substance $\mathrm{P}$ release from trigeminal primary afferent C-fibers. Eur J Pharmacol 366:27-34.

Bederson JB, Fields HL, Barbaro NM (1990) Hyperalgesia during naloxone-precipitated withdrawal from morphine is associated with increased on-cell activity in the rostral ventromedial medulla. Somatosens Mot Res 7:185-203.

Bian D, Ossipov MH, Zhong C, Malan Jr TP, Porreca F (1998) Tactile allodynia, but not thermal hyperalgesia, of the hindlimbs is blocked by spinal transection in rats with nerve injury. Neurosci Lett 241:79-82.

Bian D, Ossipov MH, Ibrahim M, Raffa RB, Tallarida RJ, Malan Jr TP, Lai J, Porreca F (1999) Loss of antiallodynic and antinociceptive spinal/supraspinal morphine synergy in nerve-injured rats: restoration by MK-801 or dynorphin antiserum. Brain Res 831:55-63.

Chaplan SR, Bach FW, Pogrel JW, Chung JM, Yaksh TL (1994) Quantitative assessment of tactile allodynia in the rat paw. J Neurosci Methods 53:55-63.

Chaplan SR, Bach FW, Shafer SL, Yaksh TL (1995) Prolonged alleviation of tactile allodynia by intravenous lidocaine in neuropathic rats. Anesthesiology 83:775-785.

Chapman V, Suzuki R, Chamarette HL, Rygh LJ, Dickenson AH (1998) Effects of systemic carbamazepine and gabapentin on spinal neuronal responses in spinal nerve ligated rats. Pain 75:261-272.

Cho HJ, Basbaum AI (1988) Increased staining of immunoreactive dynorphin cell bodies in the deafferented spinal cord of the rat. Neurosci Lett 84:125-130.

Claude P, Gracia N, Wagner L, Hargreaves KM (1999) Effect of dynorphin on ICGRP release from capsaicin-sensitive fibers. In: Abstracts of the Ninth World Congress on Pain (Devor M, Rowbotham MC, Wiesenfeld-Hallin Z, eds), p 262. Vienna: International Association for the Study of Pain.

Devor M (1991) Neuropathic pain and injured nerve: peripheral mechanisms. Br Med Bull 47:619-630.

Devor M, Seltzer Z (1999) Pathophysiology of damaged nerves in relation to chronic pain. In: Textbook of pain (Wall PD, Melzack R, eds), pp 129-164. London: Churchill Livingstone.

Devor M, Wall PD, Catalan N (1992) Systemic lidocaine silences ectopic neuroma and DRG discharge without blocking nerve conduction. Pain 48:261-268.

Dickenson AH, Matthews EA, Suzuki R (2001) Central nervous system mechanisms of pain in peripheral neuropathy. In: Neuropathic pain: pathophysiology and treatment (Hansson PT, Fields HL, Hill RG, Marchettini P, eds), pp 85-106. Seattle: International Association for the Study of Pain.

Faden AI (1992) Dynorphin increases extracellular levels of excitatory amino acids in the brain through a non-opioid mechanism. J Neurosci 12:425-429.

Fields HL (1992) Is there a facilitating component to central pain modulation? APS J 1:71-78.

Fields HL, Heinricher MM (1985) Anatomy and physiology of a nociceptive modulatory system. Philos Trans R Soc Lond B Biol Sci 308:361-374.

Fields HL, Heinricher MM (1989) Brainstem modulation of nociceptordriven withdrawal reflexes. Ann NY Acad Sci 563:34-44.

Fields HL, Bry J, Hentall I, Zorman G (1983) The activity of neurons in the rostral medulla of the rat during withdrawal from noxious heat. J Neurosci 3:2545-2552.

Han HC, Lee DH, Chung JM (2000) Characteristics of ectopic discharges in a rat neuropathic pain model. Pain 84:253-261.

Hargreaves K, Dubner R, Brown F, Flores C, Joris J (1988) A new, sensitive method for measuring thermal nociception in cutaneous hyperalgesia. Pain 32:77-88.

Heinricher MM, Roychowdhury SM (1997) Reflex-related activation of putative pain facilitating neurons in rostral ventromedial medulla requires excitatory amino acid transmission. Neuroscience 78:1159-1165.

Heinricher MM, Barbaro NM, Fields HL (1989) Putative nociceptive modulating neurons in the rostral ventromedial medulla of the rat: firing of on- and off-cells is related to nociceptive responsiveness. Somatosens Mot Res 6:427-439.

Heinricher MM, Morgan MM, Fields HL (1992) Direct and indirect actions of morphine on medullary neurons that modulate nociception. Neuroscience 48:533-543.

Heinricher MM, Morgan MM, Tortorici V, Fields HL (1994) Disinhibition of off-cells and antinociception produced by an opioid action within the rostral ventromedial medulla. Neuroscience 63:279-288.

Kajander KC, Sahara Y, Iadarola MJ, Bennett GJ (1990) Dynorphin increases in the dorsal spinal cord in rats with a painful peripheral neuropathy. Peptides 11:719-728.

Kauppila T, Kontinen VK, Pertovaara A (1998) Influence of spinalization on spinal withdrawal reflex responses varies depending on the submodality of the test stimulus and the experimental pathophysiological condition in the rat. Brain Res 797:234-242.

Kim DH, Fields HL, Barbaro NM (1990) Morphine analgesia and acute physical dependence: rapid onset of two opposing, dose-related processes. Brain Res 516:37-40.

Kim SH, Chung JM (1992) An experimental model for peripheral neuropathy produced by segmental spinal nerve ligation in the rat. Pain $50: 355-363$

Kirk EJ (1974) Impulses in dorsal spinal nerve rootlets in cats and rabbits arising from dorsal root ganglia isolated from the periphery. J Comp Neurol 155:165-175.

Kovelowski CJ, Ossipov MH, Hruby VJ, Porreca F (1999) Lesions of the dorsolateral funiculus block supraspinal opioid $\delta$ receptor mediated antinociception in the rat. Pain 83:115-122.

Kovelowski CJ, Ossipov MH, Sun H, Lai J, Malan TP, Porreca F (2000) Supraspinal cholecystokinin may drive tonic descending facilitation mechanisms to maintain neuropathic pain in the rat. Pain 87:265-273.

Liu C, Wall PD, Ben-Dor E, Michaelis M, Amir R, Devor M (2000) Tactile allodynia in the absence of $\mathrm{C}$-fiber activation: altered firing properties of DRG neurons following spinal nerve injury. Pain 85:503-521.

Liu X, Eschenfelder S, Blenk KH, Janig W, Habler H (2000) Spontaneous activity of axotomized afferent neurons after L5 spinal nerve injury in rats. Pain 84:309-318.

Malan TP, Ossipov MH, Gardell LR, Ibrahim M, Bian D, Lai J, Porreca F (2000) Extraterritorial neuropathic pain correlates with multisegmental elevation of spinal dynorphin in nerve-injured rats. Pain 86:185-194

Mansikka H, Pertovaara A (1997) Supraspinal influence on hindlimb withdrawal thresholds and mustard oil-induced secondary allodynia in rats. Brain Res Bull 42:359-365.

Ossipov MH, Lopez Y, Nichols ML, Bian D, Porreca F (1995) The loss of antinociceptive efficacy of spinal morphine in rats with nerve ligation injury is prevented by reducing spinal afferent drive. Neurosci Lett 199:87-90.

Ossipov MH, Hong Sun T, Malan Jr P, Lai J, Porreca F (2000) Mediation of spinal nerve injury induced tactile allodynia by descending facilitatory pathways in the dorsolateral funiculus in rats. Neurosci Lett 290:129-132.

Ossipov MH, Lai J, Malan Jr TP, Vanderah TW, Porreca F (2001) Tonic descending facilitation as a mechanism of neuropathic pain. In: Neuropathic pain: pathophysiology and treatment (Hansson PT, Fields HL, Hill RG, Marchettini P, eds), pp 107-124. Seattle: International Association for the Study of Pain.

Pan ZZ, Williams JT, Osborne PB (1990) Opioid actions on single nucleus raphe magnus neurons from rat and guinea-pig in vitro. J Physiol (Lond) 427:519-532.

Paxinos G, Watson C (1986) The rat brain in stereotaxic coordinates, Ed 2. San Diego: Academic.

Pertovaara A (1998) A neuronal correlate of secondary hyperalgesia in the rat spinal dorsal horn is submodality selective and facilitated by supraspinal influence. Exp Neurol 149:193-202.

Pertovaara A, Wei H, Hamalainen MM (1996) Lidocaine in the rostroventromedial medulla and the periaqueductal gray attenuates allodynia in neuropathic rats. Neurosci Lett 218:127-130.

Pertovaara A, Keski-Vakkuri U, Kalmari J, Wei H, Panula P (2001) Response properties of neurons in the rostroventromedial medulla of neuropathic rats: attempted modulation of responses by [1DMe]NPYF, a neuropeptide FF analogue. Neuroscience 105:457-468.

Porreca F, Burgess SE, Gardell LR, Vanderah TW, Malan Jr TP, Ossipov 
MH, Lappi DA, Lai J (2001) Inhibition of neuropathic pain by selective ablation of brainstem medullary cells expressing the $\mu$-opioid receptor. J Neurosci 21:5281-5288.

Porreca F, Ossipov MH, Gebhart GF (2002) Chronic pain and medullary descending facilitation. Trends Neurosci 25:319-325.

Rowbotham MC, Davies PS, Fields HL (1995) Topical lidocaine gel relieves postherpetic neuralgia. Ann Neurol 37:246-253.

Rowbotham MC, Davies PS, Verkempinck C, Galer BS (1996) Lidocaine patch: double-blind controlled study of a new treatment method for post-herpetic neuralgia. Pain 65:39-44.

Skilling SR, Sun X, Kurtz HJ, Larson AA (1992) Selective potentiation of NMDA-induced activity and release of excitatory amino acids by dynorphin: possible roles in paralysis and neurotoxicity. Brain Res 575:272-278.

Sun H, Ren K, Zhong CM, Ossipov MH, Malan TP, Lai J, Porreca F (2001) Nerve injury-induced tactile allodynia is mediated via ascending spinal dorsal column projections. Pain 90:105-111.

Tal M, Bennett GJ (1994) Extra-territorial pain in rats with a peripheral mononeuropathy: mechano-hyperalgesia and mechano-allodynia in the territory of an uninjured nerve. Pain 57:375-382.

Vanderah TW, Gardell LR, Suenaga NM, Zhong CM, Malan Jr TP, Lai J, Porreca F (2001) Enhanced evoked cgrp after spinal nerve injury is mediated by spinal dynorphin. Soc Neurosci Abstr 27:1894.

Wall PD, Gutnick M (1974a) Properties of afferent nerve impulses originating from a neuroma. Nature 248:740-743.

Wall PD, Gutnick M (1974b) Ongoing activity in peripheral nerves: the physiology and pharmacology of impulses originating from a neuroma Exp Neurol 43:580-593.

Wang Z, Gardell LR, Ossipov MH, Vanderah TW, Brennan MB, Hochgeschwender U, Hruby VJ, Malan Jr TP, Lai J, Porreca F (2001)

Pronociceptive actions of dynorphin maintain chronic neuropathic pain. J Neurosci 21:1779-1786.

Woolf CJ (1991) Generation of acute pain: central mechanisms. Br Med Bull 47:523-533.

Woolf CJ, Thompson SW (1991) The induction and maintenance of central sensitization is dependent on $N$-methyl-D-aspartic acid receptor activation: implications for the treatment of post-injury pain hypersensitivity states. Pain 44:293-299.

Wu G, Ringkamp M, Hartke TV, Murinson BB, Campbell JN, Griffin JW, Meyer RA (2001) Early onset of spontaneous activity in uninjured $\mathrm{C}$-fiber nociceptors after injury to neighboring nerve fibers. J Neurosci 21:RC140:1-5.

Yoon YW, Na HS, Chung JM (1996) Contributions of injured and intact afferents to neuropathic pain in an experimental rat model. Pain 64:27-36.

Zhuo M, Gebhart GF (1992) Characterization of descending facilitation and inhibition of spinal nociceptive transmission from the nuclei reticularis gigantocellularis and gigantocellularis pars $\alpha$ in the rat. J Neurophysiol 67:1599-1614.

Zhuo M, Gebhart GF (1997) Biphasic modulation of spinal nociceptive transmission from the medullary raphe nuclei in the rat. J Neurophysiol 78:746-758. 